\title{
A Multiple Deprivation Index and Its Relation to Health Services Accessibility in a Rural Area of Ecuador
}

\author{
Pablo CABRERA BARONA \\ University of Salzburg / Austria ·pablo.cabrera-barona@stud.sbg.ac.at
}

This contribution was double-blind reviewed as extended abstract.

\begin{abstract}
This study produced a Multiple Deprivation Index (MDI) from census information in a rural area, north-west of the Metropolitan District of Quito (MDQ), Ecuador. The index developed uses selected socio-demographic information that represents social deprivation. First, a set of indicators was chosen, and then an Analytic Hierarchy Process (AHP) was applied to calculate weights for each indicator. The MDI was calculated using an additive linear combination of the weighted indicators. Finally, using ordinary least squares (OLS), the index values were related to distances from each census area to the nearest health service to find relations between deprivation and distances to these kinds of services. Results showed that health services are located in less deprived areas, nevertheless no complete relation was founded between the index and distances to health services.
\end{abstract}

\section{Introduction}

Area-based deprivation indices have become useful tools to investigate patterns and magnitudes of socioeconomic inequalities in health (SCHUURMAN et al. 2007). Deprivation is considered as any social or economic disadvantage of an individual or human group (TOWNSEND P. 1987). Census areas are considered as first "explicative environment" units of social features, and the variables that can be extracted from census information have successfully been used to develop deprivation indexes (PAMPALON et al. 2009, SCHUURMAN et al. 2007). Deprivation indexes could also be related with health accessibility (NIGGEBRUGGE et al. 2005), because accessibility to health services is proportional to the opportunities of access, which in turn could be a function of predisposing and enabling social factors (e.g., social structure, level of education, income) (ARCURY et al. 2005). The principal objective of this study is to develop a Multiple Deprivation Index (MDI) from area-based census information in a rural area, north-west of the Metropolitan District of Quito (MDQ), Ecuador. A second objective is to relate this index with distances to health services (health centres). 


\section{Methods}

\subsection{Input data and data processing}

The 2010 Ecuadorian population and housing census was used to extract indicators for the calculation of the MDI. The indicators used were selected on the basis of a literature review (PASETTO et al. 2010, PAMPALON et al. 2009, SCHUURMAn et al. 2007), following three criteria: availability of data in census information, affinity with social deprivation, social vulnerability and health issues (PAMPALON et al. 2009), and personal knowledge of the study area. The following indicators were selected: number of illiterate people, number of people in a vulnerable age range (number of people between 0 and 14 years old, and those over 65 years old, considering elderly and young people as dependent and more vulnerable, compared to other age groups), number of ethnic minority people (number of indigenous people and black people), number of people with permanent disability, overcrowding (number of houses with more than 3 persons per room) and number of houses without access to public water supply. The indicators were transformed into percentages and variances inflation factors (VIF) were calculated within all the indicators to identify multicollinearities: the maximum value of VIF founded was 1.76 (between the indicators of illiterate people and permanent disability), which enabled us to use all the selected indicators in the index. Each indicator was structured in a single table, geocoded, and then joined to a shape file of the study area census tracks.

\subsection{Calculation of the index}

The Analytic Hierarchy Process (AHP) is a Multicriteria Decision Analysis (MDA) method (SAATY 1980), that offers very practical solutions for decision-making problems (FEIZIZADEH \& BLASCHKE 2011), and in this study it is used to derive the weights of the MDI, based on 27 experts' opinions. The consistency ratio (CR) obtained was less than 0.10 , therefore, confident weights were obtained. Table 1 shows the pairwise comparison criteria, the weights obtained and the CR.

Tab. 1: Results of the AHP method

\begin{tabular}{|c|c|c|c|c|c|c|c|}
\hline Indicator & $\begin{array}{l}\text { Illiterate } \\
\text { people (I) }\end{array}$ & $\begin{array}{l}\text { Vulnerable } \\
\text { age }(V)\end{array}$ & $\begin{array}{c}\text { Ethnic } \\
\text { minority } \\
\text { (E) }\end{array}$ & \begin{tabular}{|c|} 
Permanent \\
disability (D)
\end{tabular} & $\begin{array}{l}\text { Overcrowding } \\
\text { (O) }\end{array}$ & $\begin{array}{c}\text { No } \\
\text { access } \\
\text { pub. } \\
\text { water } \\
\text { (NW) }\end{array}$ & Weights \\
\hline $\begin{array}{l}\text { Illiterate people } \\
\text { (I) }\end{array}$ & 1 & & & & & & 0.1661 \\
\hline $\begin{array}{c}\text { Vulnerable age } \\
\text { (V) }\end{array}$ & $1 / 2$ & 1 & & & & & 0.0928 \\
\hline $\begin{array}{l}\text { Ethnic minority } \\
\text { (E) }\end{array}$ & $1 / 2$ & $1 / 2$ & 1 & & & & 0.0728 \\
\hline $\begin{array}{c}\text { Permanent } \\
\text { disability (D) }\end{array}$ & $1 / 2$ & 2 & 2 & 1 & & & 0.1325 \\
\hline $\begin{array}{l}\text { Overcrowding } \\
\text { (O) }\end{array}$ & 2 & 3 & 3 & 2 & 1 & & 0.2369 \\
\hline $\begin{array}{l}\text { No access to } \\
\text { public water } \\
\text { supply (NW) }\end{array}$ & 2 & 3 & 3 & 2 & 2 & 1 & 0.2989 \\
\hline
\end{tabular}


The Multiple Deprivation Index (MDI) equals the sum of the weighted indicators:

$M D I=0.1661(I)+0.0928(V)+0.0728(E)+0.1325(D)+0.2369(O)+0.2989(N W)$

Linear min-max normalization was applied to the MDI index. Values closer to 1 represent higher deprivation.

\subsection{Relation between the MDI and accessibility to health services}

First, the centroids for each census track were calculated. Second, Euclidean distance was used to calculate distances from each census track centroid to the nearest health service. Third, an ordinary least squares (OLS) estimation between index values (dependent variable) and distances (independent variable) were performed to identify any relation between the two measures.

\section{Results}

The MDI differs between census tracks, with a mean $=0.58$ and a standard deviation $=$ 0.25 . Figure 1 shows that, in general, lower values of MDI spatially match with the presence of health services.

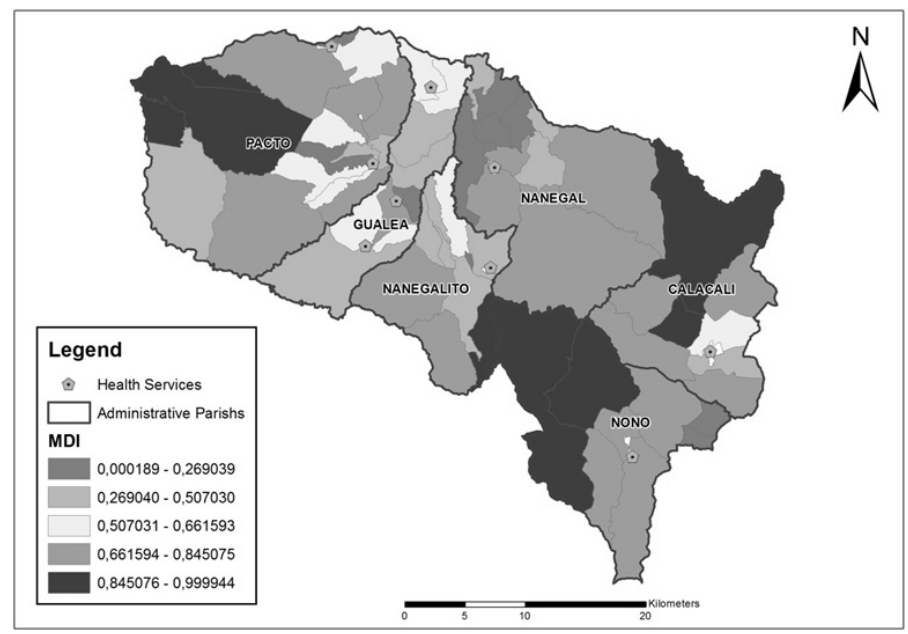

Fig. 1:

Visualisation of the census-area based MDI. Less deprivation is observed where more health services are located.

OLS results accomplished conditions of normality (Jarque-Bera test p value: 0.08 ) and homoscedasticity (Breusch-Pagan test $p$ value: 0.10 ). Even when $p$ value of the independent variable (distances to the nearest health service) is significant (0.0008), a low R-squared value was obtained for this relation (0.16). 


\section{Conclusion and Outlook}

The AHP method offered a practical way to calculate weights and results showed that more deprived areas coincided with a lower presence of health services. No strong relationship was founded between MDI and distances: this means that distance to health services can explain only certain aspects of deprivation. Further work in this study will focus on 1 . comparison of different methods to obtain weights, 2. evaluation of the MAUP and 3. analysis of MDI and accessibility to health services using non-Euclidean approaches. This study demonstrated one possibility to assess deprivation from census information, and showed how the obtained MDI values relate to distance to health services. This study aims to contribute to a better understanding and identification of social inequalities in the study area and the MDI could be used as a tool for supporting decision making in public health planning, because the index relates social deprivation and health issues.

\section{References}

Arcury, T., Gesler, W. M., Preisser, J. S., Sherman, J., Spencer, J. \& Periin, J. (2005), The effects of geography and spatial behavior on health care utilization among the residents of a rural region. Health Services Research, 40 (1), 135-156.

FEIzIZADEH, B. \& BlASCHKE, T. (2011), Landslide risk assessment based on GIS multicriteria evaluation: a case study in Bostan-Abad County, Iran. Journal of earth science and engineering, 1, 66-71.

Niggebrugge A., Haynes R., Jones A., Lovett \& Harvey I. (2005), The index of multiple deprivation 2000 access domain: a useful indicator for public health? Social Science \& Medicine, 60, 2743-2753.

Pampalon, P., PAmel, D., Gamache, P. \& Raymond, G. (2009), A deprivation index for health planning in Canada. Chronic Diseases in Canada, 29 (4).

Pasetto, P., Sampaolo, L. \& Pirastu, R. (2010), Measures of material and social circumstances to adjust for deprivation in small-area studies of environment and health: review and perspectives. Ann Ist Super Sanità, 46 (29), 185-197

SAATY, T. L. (1980), The analytical hierarchy process. New York, McGraw Hill.

Schuurman, N., Bell, N., Dunn, J.R. \& Oliver, L. (2007), Deprivation Indices, Population Health and Geography: An Evaluation of the Spatial Effectiveness of Indices at Multiple Scales. Journal of Urban Health: Bulletin of the New York Academy of Medicine, 84 (4), 591-603.

Townsend, P. (1987), Deprivation. Journal of Social Policy, 16, 125-146. 